\title{
H2-REDUCTION BEHAVIOR OF FeS-CaO MIXTURE DURING MICROWAVE HEATING
}

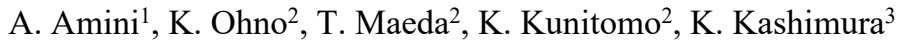 \\ ${ }^{1}$ Department of Materials Process Engineering, Graduate School of Engineering, Kyushu \\ University, 744 Motooka, Nishi-Ku, Fukuoka, Japan \\ ${ }^{2}$ Department of Materials Science and Engineering, Faculty of Engineering, Kyushu \\ University, 744 Motooka, Nishi-Ku, Fukuoka, Japan \\ ${ }^{3}$ Faculty of Engineering, Chubu University, 1200 Matsumoto-cho, Kasugai, Aichi 487- \\ 8501, Japan \\ ahmadreza.amini.ir@gmail.com
}

Keywords: microwave heating, $\mathrm{H}_{2}$-reduction, kinetic study

\begin{abstract}
Kinetics of iron production via hydrogen-reduction of $\mathrm{FeS}-\mathrm{CaO}$ mixture during microwave heating was investigated at 750,570 , and $460{ }^{\circ} \mathrm{C}$ to clarify the dominant rate-controlling mechanism. Results revealed that the interfacial chemical reaction is rapidly progressed during microwave irradiation and gas diffusion is the dominant rate-controlling mechanism with an activation energy of $22.3 \mathrm{~kJ} \mathrm{~mol}^{-1}$. This study demonstrated that the microwave irradiation enhances the rate of chemical reaction during iron production from FeS-CaO mixture.
\end{abstract}

\section{Introduction}

Reduction of sulfide minerals in the presence of lime $(\mathrm{CaO})$ has been studied in previous literature ${ }^{[1,2]}$. Hara et al. ${ }^{[1]}$ produced metallic $\mathrm{Cu}, \mathrm{Co}$ and $\mathrm{Fe}$ from a sulfide concentrate via a carbothermic reduction in the presence of $\mathrm{CaO}$ at $1000^{\circ} \mathrm{C}$. Jha et al. ${ }^{[3]}$ showed that the reduction of $\mathrm{FeS}: \mathrm{CaO}: \mathrm{C}=1: 1: 2$ mixture initiates after a heat treatment at $850{ }^{\circ} \mathrm{C}$ for $>90$ min. On the other hand, reduction rate of iron oxide in $\mathrm{H}_{2}$ is much higher than that in $\mathrm{CO}$ ${ }^{[4,5]}$. Accordingly, hydrogen-reduction of $\mathrm{FeS}$ in the presence of lime is likely an alternative method for iron production from iron sulfide minerals that can be considered as a twostage reaction ${ }^{[6]}$; ion exchange reaction, Eq. (1), and reduction reaction, Eq. (2) ${ }^{[7]}$. The total reaction is represented by Eq. (3).

$$
\begin{array}{lll}
\mathrm{FeS}_{(\mathrm{s})}+\mathrm{CaO}_{(\mathrm{s})}=\mathrm{FeO}_{(\mathrm{s})}+\mathrm{CaS}_{(\mathrm{s})} & \triangle \mathrm{G}_{1}{ }^{\circ}=-4615-0.205 \mathrm{~T} & \mathrm{~J}^{\circ} \mathrm{mol}^{-1} \\
\mathrm{FeO}_{(\mathrm{s})}+\mathrm{H}_{2(\mathrm{~g})}=\mathrm{Fe}_{(\mathrm{s})}+\mathrm{H}_{2} \mathrm{O}_{(\mathrm{g})} & \triangle \mathrm{G}_{2}{ }^{\circ}=16240-8.45 \mathrm{~T} & \mathrm{~J} . \mathrm{mol}^{-1} \\
\mathrm{FeS}_{(\mathrm{s})}+\mathrm{CaO}_{(\mathrm{s})}+\mathrm{H}_{2(\mathrm{~g})}=\mathrm{Fe}_{(\mathrm{s})}+\mathrm{CaS}_{(\mathrm{s})}+\mathrm{H}_{2} \mathrm{O}_{(\mathrm{g})} & \triangle \mathrm{G}_{3}{ }^{\circ}=11625-8.655 \mathrm{~T} & \mathrm{~J} . \mathrm{mol}^{-1}
\end{array}
$$

In addition, microwave irradiation is an energy-efficient and a rapid-heating method to decrease activation energy of chemical reactions owing to both thermal and non-thermal effects of microwave photons. The non-thermal effect of microwave irradiation on the rate of chemical reactions, has attracted the attention of researchers on microwave irradiation energy in terms of speeding up chemical reactions ${ }^{[8-10]}$. The thermal effect of microwave irradiation has the potential to mitigate $\mathrm{CO}_{2}$ emission and decrease the amount of carbonaceous materials required for carbothermic reduction of iron resources due to its specific characteristics, such as rapid and selective heating, volumetric heating, and highefficiency heating.

As a novel idea for a further mitigation of $\mathrm{CO}_{2}$ emission, hydrogen-reduction of $\mathrm{FeS}-\mathrm{CaO}$ mixture during microwave irradiation is investigated in the present study to combine the advantages of microwave irradiation and using $\mathrm{H}_{2}$ as reducing agent. 


\section{Materials and Methods}

Reagent $\mathrm{CaCO}_{3}$ powder (purity, $99.5 \%$, calcined at $1300{ }^{\circ} \mathrm{C}$, crushed and ground to obtain a $\mathrm{CaO}$ with grain size of less than $45 \mu \mathrm{m}$ ) and $\mathrm{FeS}$ powder (purity, 99\%, crushed and ground to the grain size of less than $45 \mu \mathrm{m}$ ) were mixed well by a stainless steel spoon to prepare a powder mixture of $\mathrm{FeS}$ : $\mathrm{CaO}$ with stoichiometric mole ratio of $1: 1$. The mixture $(2 \mathrm{~g})$ was pressed to a cylindrical shape briquette sample $(10 \mathrm{~mm}$ diameter, $10 \mathrm{~mm}$ height, $2.54 \mathrm{~g}^{\mathrm{c}} \mathrm{cm}^{-3}$ apparent density) using a cold hydraulic press. The reaction progress was estimated based on the weight change of samples during microwave treatment in $\mathrm{H}_{2}$ (1 NL. min $^{-1}$ ) using a traditional multi-mode microwave generator with a maximum output power of $1.5 \mathrm{~kW}$ at $2.45 \mathrm{GHz}$. In the present study, the microwave heating system was equipped with thermobalance to prepare a unique apparatus for a novel continuous study of the hydrogen-reduction during microwave irradiation. The sample was placed in a silica basket (silica is a transparent material during microwave irradiation), and the basket was suspended in a silica tube (inner diameter, $35 \mathrm{~mm}$ ) by silica chains connected to the thermobalance which installed on top of the microwave apparatus. Temperature of the sample was measured using an infrared radiation thermometer with the measurement range of $330-1500{ }^{\circ} \mathrm{C}$. The experiments were conducted at various temperatures by applying the microwave out-put powers of 1275,1125 , and $975 \mathrm{~W}$. After the certain durations, the microwave heating system was turned off and the atmosphere was changed to $\mathrm{N}_{2}$ (1 NL. min $^{-1}$ ) to cool down the sample. In the present study, the microwave treatment was conducted at least twice at each output power and the average temperature was considered as the temperature corresponding to the applied power. The average temperature of 750 , 570 , and $460{ }^{\circ} \mathrm{C}$ were attained after a 1200 s-treatment during microwave irradiation at 1275,1125 , and $975 \mathrm{~W}$, respectively.

\section{Reduction degree}

Reduction degree (X, dimensionless) was calculated according to Eq. 4:

Reduction degree $(X)-\frac{W_{t}-W_{t}-W_{h t}}{W_{i} \times W_{O}}$

where $\mathrm{W}_{\mathrm{i}}(\mathrm{g}), \mathrm{W}_{\mathrm{t}}(\mathrm{g})$, and $\mathrm{W}_{\mathrm{ht}}(\mathrm{g})$ are the initial weight of the sample, the weight of the sample after treatment for $t$ seconds, and the weight change of the sample after treatment for $t$ seconds owing to the dehydration reaction. $W_{O}$ (dimensionless) is the stoichiometric weight ratio of oxygen in the sample, which is 0.111 . Fig. 1 shows the reduction degree of samples during microwave irradiation in $\mathrm{H}_{2}$ at $1275 \mathrm{~W}\left(750^{\circ} \mathrm{C}\right), 1125 \mathrm{~W}\left(570{ }^{\circ} \mathrm{C}\right)$, and $975 \mathrm{~W}\left(460^{\circ} \mathrm{C}\right)$ for $1200 \mathrm{~s}$. 


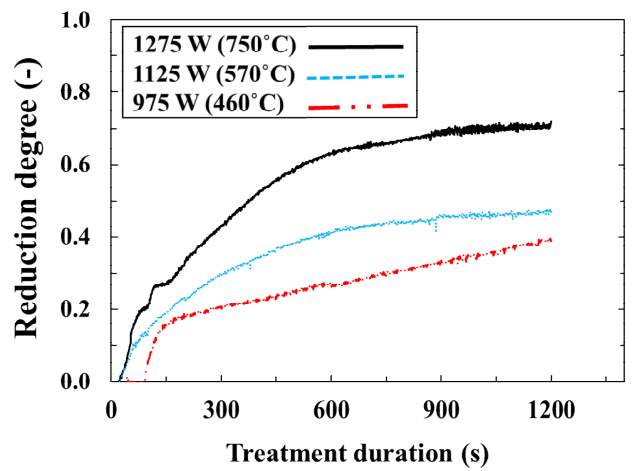

Fig. 1. Reduction degree of samples during microwave irradiation at 750,570 , and $460{ }^{\circ} \mathrm{C}$ for $1200 \mathrm{~s}$.

A noticeable increase in the reduction degree observed in the first $600 \mathrm{~s}$ of treatment in $\mathrm{H}_{2}$ whereas no significant change occurred during a longer processing time. Therefore, in the present kinetic study, the initial $600 \mathrm{~s}$ of the treatment was investigated owing to the insignificant change in reduction degree after $600 \mathrm{~s}$. Reduction reaction during treatment of the sample in $\mathrm{H}_{2}$ is attributed to the oxygen removal as $\mathrm{H}_{2} \mathrm{O}$ according to Eq. 2 that subsequently results in phase transformations in the sample. X-ray diffraction pattern of un-treated sample and that of microwave treated sample at $750{ }^{\circ} \mathrm{C}$ for certain durations are shown in Fig. 2.



Fig. 2. XRD patterns of (a-d) microwave treated sample in $\mathrm{H}_{2}$ at $1275 \mathrm{~W}\left(750{ }^{\circ} \mathrm{C}\right)$ for certain durations and (e) that of un-treated sample.

$\mathrm{Ca}(\mathrm{OH})_{2}$ was detected in the pattern of un-treated sample (Fig. 2(e)), although the crushed $\mathrm{CaO}$ powder was kept in a vacuum desiccator chamber to protect it from hydration. This is attributed to the hydration of a portion of $\mathrm{CaO}$ during sample preparation steps such as cold-pressing of the powder mixture. Treatment of sample in the inert gas $\left(\mathrm{N}_{2}, 1 \mathrm{NL} \cdot \mathrm{min}^{-1}\right)$ confirmed a decrease in weight of the sample in the first $80 \mathrm{~s}$ of microwave treatment at 750 and $570{ }^{\circ} \mathrm{C}$, and in the first $100 \mathrm{~s}$ of microwave processing at $460{ }^{\circ} \mathrm{C}$. Therefore, weight change in these times is likely attributed to either reduction reaction or dehydration of $\mathrm{Ca}(\mathrm{OH})_{2}$ according to Eq. $5^{[11]}$. 


$$
\mathrm{Ca}(\mathrm{OH})_{2(\mathrm{~s})}=\mathrm{CaO}_{(\mathrm{s})}+\mathrm{H}_{2} \mathrm{O}_{(\mathrm{g})}
$$

$\mathrm{CaS}$ and $\mathrm{Fe}$ were detected in pattern of samples treated for $>200 \mathrm{~s}$ indicating a great progress in both ion exchange reaction (Eq. 1) and reduction reaction (Eq. 2). Furthermore, an intermediate oxysulfide phase ( $\mathrm{FeO} \cdot \mathrm{CaS})$ was detected in the XRD pattern of sample treated for 200 and $600 \mathrm{~s} \mathrm{(Fig.} \mathrm{2(b)} \mathrm{and} \mathrm{(c)).} \mathrm{This} \mathrm{phase} \mathrm{is} \mathrm{an} \mathrm{intermediate} \mathrm{phase} \mathrm{during}$ ion exchange reaction and confirms a great progress in this reaction at $750{ }^{\circ} \mathrm{C}$. Formation of oxysulfide phases is also reported during carbothermic reduction of sulfide minerals in the presence of lime in previous studies ${ }^{[3,6,12]}$.

Fig. 3 shows the SEM-EDX images of large FeS particles from reacted part of a sample microwave treated at $750{ }^{\circ} \mathrm{C}$ for $600 \mathrm{~s}$. It seems the ion exchange reaction (Eq. 1) is initiated on the surface of FeS particles and forms iron oxide. Then, the iron oxide (product of the ion exchange reaction) is reduced by $\mathrm{H}_{2}$ to form a layer of metallic iron which surrounds the un-reacted part of FeS particles.

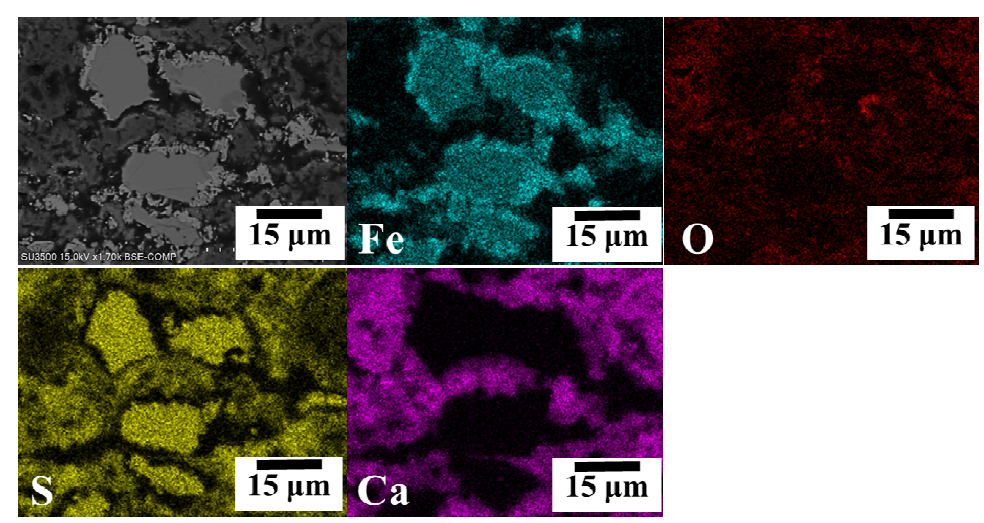

Fig. 3. SEM-EDX images of large FeS particles in samples microwave treated at $750{ }^{\circ} \mathrm{C}$ for $600 \mathrm{~s}$.

\section{Morphology observations}

Macroscale observation of samples microwave treated for $50 \mathrm{~s}$ at $1275 \mathrm{~W}\left(750{ }^{\circ} \mathrm{C}\right)$ is illustrated in Fig. 4. A boundary was recognized between the reacted part (bright gray, outer part) and un-reacted core (dark gray). Further observations showed that the boundary is moved toward the center of the sample with an increase in processing time that resulted in the shrinking of the un-reacted core. Accordingly, the total reaction is progressed topochemically and the un-reacted core model can be employed for kinetic study of iron production during microwave treatment of $\mathrm{FeS}-\mathrm{CaO}$ mixture in $\mathrm{H}_{2}$. 


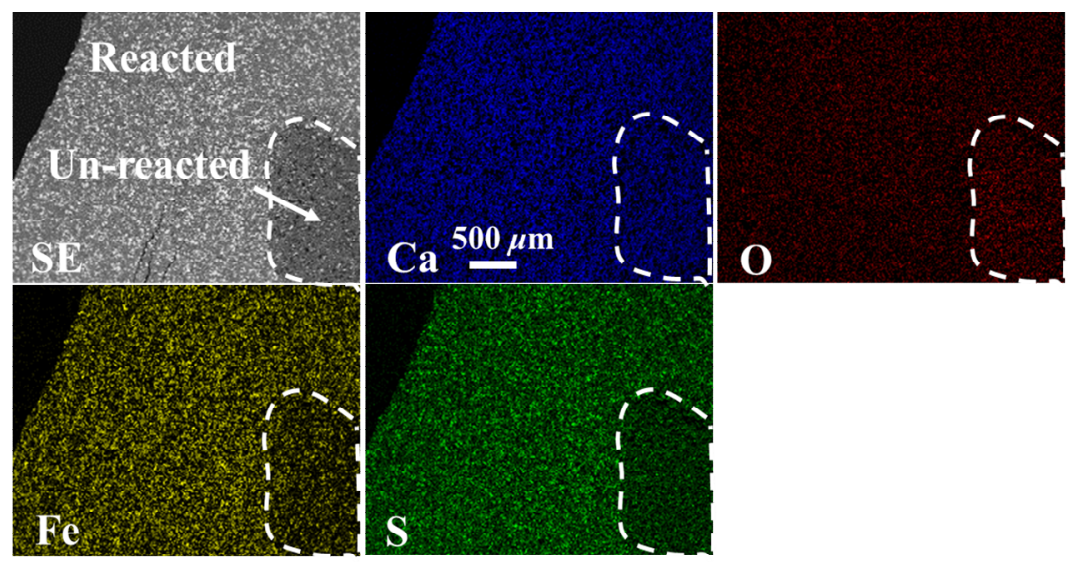

Fig. 4. SEM-EDX macrographs of microwave treated samples at $750{ }^{\circ} \mathrm{C}$ for $50 \mathrm{~s}$.

\section{Kinetic model}

Un-reacted core model has been largely applied in previous investigations ${ }^{[13-16]}$ to study the kinetics of chemical reactions which progress topochemically. In this model, four mechanisms can contribute to reaction progress: gas diffusion in micro pores of solid product, gas-solid interfacial chemical reaction, mass transfer, and a mix of these mechanisms. To evaluate kinetic parameters in dominant rate-controlling mechanism, mathematical kinetic equations have been derived [17] based on the characteristics of reactants and products in gas-solid reactions. The derived kinetic equations corresponding to the reaction rate-controlling mechanisms for spherical shape particles are summarized as follows:

Gas diffusion in micro pores (GD):

$1-3(1-X)^{2 / 3}+2(1-X)=\frac{6 D_{a}}{C_{R} r_{i}^{2}}\left(\frac{K}{1+K}\right)\left(C_{A b}-C_{A e}\right) t$

Interfacial chemical reaction (ICR):

$1-(1-X)^{1 / s}=\frac{k\left(C_{A b}-C_{A B}\right)}{C_{R} r_{!}} t$

Mass transfer (MT):

$X=\frac{3 k_{f}}{C_{R} r_{i}}\left(\frac{K}{1+K}\right)\left(C_{A b}-C_{A Q}\right) t$

Mixed GD, ICR, and MT:

$\frac{1}{C_{R} r_{i}}\left(\frac{K}{1+K}\right)\left(C_{A b}-C_{A e}\right) \frac{t}{f}-\frac{3-3 f+f^{2}}{3 k_{f}}=\frac{r_{i}}{6 D_{\tilde{z}}}\left(3 f-2 f^{2}\right)+\frac{K}{k(1+K)}$

Where X (dimensionless), $\mathrm{K}$ (dimensionless), $\mathrm{D}_{\mathrm{e}}\left(\mathrm{cm}^{2} \cdot \mathrm{s}^{-1}\right)$, and $\mathrm{k}_{\mathrm{f}}\left(\mathrm{cm} \cdot \mathrm{s}^{-1}\right)$ are the reduction degree, the equilibrium constant for reduction reaction, the effective diffusion coefficient of gas in micro pores, and the mass transfer coefficient in the gas film, respectively. $\mathrm{C}_{\mathrm{Ab}}$ and $\mathrm{C}_{\mathrm{Ae}}\left(\mathrm{mol} . \mathrm{cm}^{-3}\right)$ are the concentration of reducing gas in bulk and at the equilibrium state, respectively. $\mathrm{k}\left(\mathrm{cm} . \mathrm{s}^{-1}\right)$ is the rate constant of chemical reaction, $\mathrm{t}(\mathrm{s})$ is the treatment duration, $r_{i}(\mathrm{~cm})$ is the radius of sample, and $f$ is equal to $\left(1-(1-X)^{1 / 3}\right) . C_{R}\left(m^{-1} \mathrm{~cm}^{-3}\right)$ is the concentration of reducible oxygen in the sample, that is $0.0177 \mathrm{~mol} . \mathrm{cm}^{-3}$. 


\section{Kinetic analysis}

With regards to the microscopic observations that confirm the topochemical progress of reaction in the present study, un-reacted core model was employed to clarify the dominant rate-controlling mechanism in reduction reaction (Eq. 2) during treatment under $\mathrm{H}_{2}$ atmosphere. To simplify calculations, the radius of the assumed spherical sample $\left(\mathrm{r}_{\mathrm{i}}, \mathrm{cm}\right)$ was calculated based on the radius $(\mathrm{r}, \mathrm{cm})$ and height $\left(\mathrm{h}_{\mathrm{b}}, \mathrm{cm}\right)$ of the cylindrical shape briquette sample according to Eq. $10{ }^{[18]}$. The equilibrium constant $(\mathrm{K})$ of $0.409,0.272$, and 0.192 were attained using Eq. 11 at 750,570 , and $460{ }^{\circ} \mathrm{C}$, respectively. The mass transfer coefficient $\left(\mathrm{k}_{\mathrm{f}}\right)$ of 14.9, 10.9, and 8.69 were attained using the Sherwood (Sh), Reynolds $(\mathrm{Re})$, and Schmidt (Sc) dimensionless numbers at 750,570 , and $460^{\circ} \mathrm{C}$, respectively.

$r_{l}=\left(\frac{3}{4} r_{b}^{2} h_{b}\right)^{1 / 3}$

$\ln K=1.016-1953.33 T^{-1}$

The kinetic study was conducted up to $600 \mathrm{~s}$ treatment duration owing to no significant weight change after treatment for duration $>600 \mathrm{~s}$.

Considering the kinetic equations (6-9), Chemical reaction, mass transfer, gas diffusion, and mixed rate-controlling mechanisms at 750,570 , and $460{ }^{\circ} \mathrm{C}$ were plotted to attain the linearity $\left(\mathrm{R}^{2}\right)$ of each plot, as presented in Table $\mathbf{1 .}$

Table 1: Coefficient determination $\left(\mathrm{R}^{2}\right)$ of kinetic mechanisms

\begin{tabular}{lcccc}
\hline & Gas diffusion & Interfacial chemical reaction & Mass transfer & Mixed \\
\hline $\mathrm{R}^{2}$ at $750{ }^{\circ} \mathrm{C}$ & 0.9732 & 0.8968 & 0.699 & 0.9654 \\
$\mathrm{R}^{2}$ at $570{ }^{\circ} \mathrm{C}$ & 0.9859 & 0.8295 & 0.7116 & 0.9835 \\
$\mathrm{R}^{2}$ at $460^{\circ} \mathrm{C}$ & 0.9524 & 0.7545 & 0.7021 & 0.068 \\
\hline
\end{tabular}

The coefficient determination (linearity) of gas diffusion in micro pores mechanism is larger than that of other mechanisms at all temperatures. This indicates that the dominant mechanism for controlling of the reduction rate during microwave irradiation in $\mathrm{H}_{2}$ is gas diffusion in micro pores.

Microwave irradiation enhances the rate of interfacial chemical reaction where the gas diffusion acts as dominant resistance for the reduction reaction from the onset of microwave irradiation. This is likely attributed to the non-thermal (catalytic) effect of the microwaves on speeding up the chemical reactions, as reported previously ${ }^{[8-10,19]}$. On the other hand, such behavior is likely related to the different interaction between particles and microwaves. In the microwave irradiation, heat can be generated from within the particle (volumetric heating) owing to the penetrative power of microwaves ${ }^{[20]}$ resulting in larger progress of the chemical reaction during microwave heating owing to the volumetric heating characteristic of microwaves which improves the interfacial chemical reaction through the sample.

\section{Activation energy}

The effective diffusion coefficients $\left(\mathrm{D}_{\mathrm{e}}\right)$ were attained at 750,570 , and $460{ }^{\circ} \mathrm{C}$ by calculating the slope of linear trend lines in the gas diffusion plot, as illustrated in Fig. 6. 


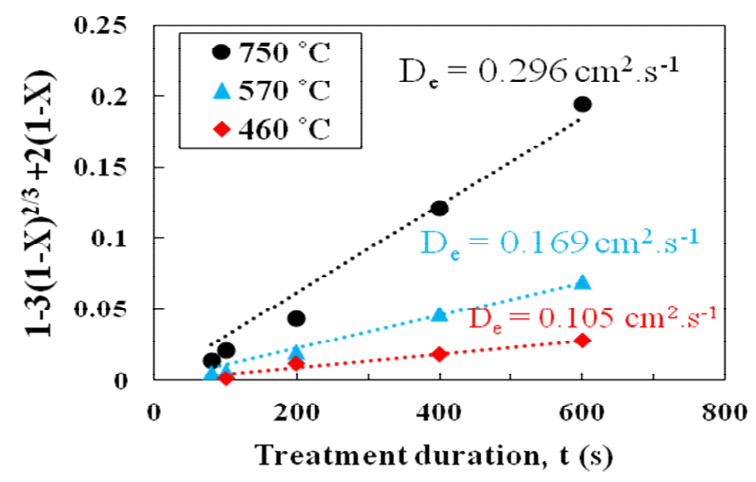

Fig. 6. Diffusion coefficient at 750,570 , and $460{ }^{\circ} \mathrm{C}$.

To calculate activation energy for gas diffusion $\left(\mathrm{E}_{\mathrm{D}}, \mathrm{kJ}\right)$ during microwave processing, the Arrhenius equation was applied wherein the $\ln \mathrm{D}_{\mathrm{e}}$ (Arrhenius equation) was plotted versus $10^{4} / \mathrm{T}$. The slope of lines gives the activation energy of $22.3 \mathrm{~kJ} \cdot \mathrm{mol}^{-1}$.

In the present study, the chemical reaction is likely progressed rapidly during microwave irradiation owing to the extraordinary effects of microwave irradiation (thermal and nonthermal) on speeding up the chemical reactions ${ }^{[8-10,19]}$ and the overall reaction is controlled by gas diffusion after the onset of microwave irradiation.

\section{Conclusions}

Kinetics of iron production during hydrogen reduction of $\mathrm{FeS}-\mathrm{CaO}$ mixture was investigated under microwave irradiation to clarify the dominant rate-controlling mechanisms. The results are summarized as follows:

1. Reduction of FeS-CaO mixture in $\mathrm{H}_{2}$ can be considered as a two-step reaction: An ion exchange reaction between $\mathrm{FeS}$ and $\mathrm{CaO}$ that forms iron oxide on the surface of FeS particles. Then, $\mathrm{H}_{2}$ reduces the iron oxide (product of the ion exchange reaction) to form a layer of metallic iron which surrounds the un-reacted part of FeS particles.

2. Hydrogen-reduction of FeS-CaO mixture during microwave irradiation is a topochemical reaction and un-reacted core model can be applied for kinetic analysis.

3. After the onset of microwave irradiation, the dominant rate-controlling mechanism is gas diffusion in micro pores with activation energy of $22.3 \mathrm{~kJ} \cdot \mathrm{mol}^{-1}$. This is likely attributed to the volumetric heating characteristic of microwaves and the extraordinary effect of microwave irradiation on speeding up the chemical reactions, particularly at lower temperatures.

\section{References}

1. Hara, Y.S.R., A. Jha, Miner. Process. Extr. Metall., 2013, 122, 146-56.

2. Hara, Y.R.S., A. Jha, Energy Technology 2015, Springer International Publishing, Cham, 2015, 83-91.

3. Jha, A., P. Grieveson, Scand. J. Metall., 1992, 21, 50-62.

4. Liu, W., J.Y. Lim, M.A. Saucedo, A.N. Hayhurst, S.A. Scott, J.S. Dennis, Chem. Eng. Sci., 2014, 120, 149-66.

5. Kim, K.Y., E.J. Jang, D.Y. Kim, S.M. Jung, Ironmak. Steelmak., 2017, 44, 6-16.

6. Hara, Y.S.R., Int. J. Miner. Metall. Mater., 2014, 21, 1-11.

7. Kuila, S.K., R. Chatterjee, D. Ghosh, Int. J. Hydrogen Energy, 2016, 41, 9256-9266.

8. Ferrari, A., J. Hunt, A. Lita, B. Ashley, A.E. Stiegman, J. Phys. Chem. C, 2014, 118, 9346-9356.

9. Zhou, J., W. Xu, Z. You, Z. Wang, Y. Luo, L. Gao, C. Yin, R. Peng, L. Lan, Sci. Rep., $2016,6,25149$. 
10. Kashimura, K., M. Sato, M. Hotta, D. Kumar Agrawal, K. Nagata, M. Hayashi, T. Mitani, N. Shinohara: Mater. Sci. Eng. A, 2012, 556, 977-979.

11. Schaube, F., L. Koch, A. Wörner, H. Müller-Steinhagen, Thermochim. Acta, 2012, 538, 9-20.

12. Jha, A., S. Tang, A. Chrysanthou, Metall. Mater. Trans. B Process Metall. Mater. Process. Sci., 1996, 27, 829-840.

13. Noguchi, D., K. Ohno, T. Maeda, K. Nishioka, M. Shimizu, ISIJ Int., 2013, 53, 13501357.

14. Bai, M.-H., H. Long, S.-B. Ren, D. Liu, C.-F. Zhao, ISIJ Int., 2018, 58, 1034-1041.

15. Bai, M., H. Long, L. Li, D. Liu, S.-B. Ren, C.-F. Zhao, J. Cheng, Int. J. Hydrogen Energy, 2018, 43, 15586-15592.

16. Fu, D., G. Tang, Y. Zhao, J. D’Alessio, C.Q. Zhou, Int. J. Heat Mass Transf., 2016, 103, 77-86.

17. Valipour, M.S., Sci. Iran., 2009, 16, 108-124.

18. Usui, T., M. Ohmi, S. Hirashima, N. Kitagawa, Tetsu-to-Haganè, 1987, 73, 19561963.

19. Hunt, J., A. Ferrari, A. Lita, M. Crosswhite, B. Ashley, A.E. Stiegman, J. Phys. Chem. C, 2013, 117, 26871-26880.

20. Gupta, M., E. Wong Wai Leong, Microwaves and Metals, John Wiley \& Sons, 2007. 